\title{
Clinical syndrome
}

INSERM

\section{Source}

INSERM. (1999). Orphanet: an online rare disease and orphan drug data base. clinical syndrome. ORPHA:377792

Clinical entity defined by a set of phenotypic abnormalities with a homogeneous evolution and homogeneous therapeutic possibilities, regardless of the physiopathological mechanism. 